\title{
Las funciones del Derecho concursal: tendencias actuales en el Derecho comparado
}

\author{
The functions of bankruptcy law: current trends in comparative law
}

\begin{abstract}
Francisco Jesús Moreno Buendía
*Doctor en Derecho. Profesor de Derecho Mercantil de la Universidad de Sevilla. Contacto: fjesusmoreno@us.es. ORCID: https://orcid.org/0000-0003-2348-8144
\end{abstract}

Fecha de recepción: 1 de febrero de 2021 Fecha de aprobación: julio 15 de 2021

Para citar este artículo / To reference this article Moreno, F.J (2021) Las funciones del Derecho concursal: tendencias actuales en el Derecho comparado. Inciso, 23(1) , e 1124

DOI: http://dx.doi.org/10.18634/incj.23v.1i11 124

\section{Resumen}

Las crisis económicas sufridas por la mayoría de los países industrializados han removido los cimientos del Derecho concursal, especialmente en lo que atañe a sus principios y funciones elementales. En este sentido, el aumento del volumen y de la complejidad de las estructuras empresariales ha incidido notablemente en las recientes reformas del Derecho concursal, las cuales han tratado de incentivar la función conservativa de los procedimientos concursales.

El propósito de este artículo es analizar las dinámicas en la configuración de la función del Derecho concursal presentes en las recientes intervenciones legislativas llevadas a cabo por algunos países Europeos y Latinoamericanos. Para alcanzar dicho objetivo se sigue fundamentalmente un método analítico-descriptivo, a través del cual se justifica la relevancia interpretativa de la función del Derecho concursal, y se exponen las funciones tradicionales atribuidas a este sector del ordenamiento jurídico y el protagonismo de la función conservativa presente en las últimas reformas. A partir de ello, se realiza un análisis económico-funcional de esta tendencia, lo cual 
permite descubrir las tensiones existentes entre la función conservativa y la función solutoria. Desde esta perspectiva, se concluye sobre la necesidad de priorizar la finalidad solutoria de los procedimientos concursales, a pesar de la relevancia que actualmente se atribuye a la protección de la empresa en crisis mediante su saneamiento o rehabilitación.

Palabras clave: Derecho mercantil; Derecho comparado; Procedimiento legal; Reforma jurídica; Régimen jurídico.

\begin{abstract}
The financial crisis suffered by most of the industrialised have removed the foundations of bankruptcy law, especially as regards its elementary principles and functions. In this sense, the increase in the volume and complexity of business structures has had a notable impact on the recent reforms of bankruptcy law, which have tried to encourage the conservation function of bankruptcy proceedings.

The purpose of this article is to analyze the dynamics in the configuration of the function of bankruptcy law present in the recent legislative interventions carried out by some European and Latin American countries. In order to achieve this objective, an analytical-descriptive method is basically used, through which the interpretative relevance of the function of bankruptcy law is justified, and it exposes the traditional functions attributed to bankruptcy law and the protagonism of the conservation function present in the latest bankruptcy reforms. From this, an economic-functional analysis of this trend is carried out, which allows to discover the tensions existing between the conservative function and the solution function of bankruptcy proceedings. From this perspective, we conclude on the need to prioritize the solution of bankruptcy proceedings, despite the relevance currently attributed to the protection of the company in difficulty through its reorganization or rehabilitation.
\end{abstract}

Keywords: Commercial law; Comparative law; Legal procedure; Law reform; Legal systems.

\title{
Introducción
}

La insolvencia es una situación que, con carácter general, presupone un fallo en el mercado y en el sistema jurídico. En un mercado perfecto, en el que existe suficiente información, las expectativas de los sujetos que participan en él se amoldan a la realidad y no se concede un exceso de crédito a un sujeto en dificultades. Desde el punto de vista jurídico, la insolvencia de una sociedad de capital (protagonistas del mercado económico global) implica que han fallado los mecanismos societarios de control de la estabilidad financiera y patrimonial, a saber: el deber de los administradores de prevenir situaciones de crisis económica, el deber de reducir el capital social o el de disolución de la sociedad.

En el contexto descrito, cuando el patrimonio del deudor es (o va a ser previsiblemente) insuficiente para satisfacer todas las pretensiones de sus acreedores, se genera una situación de insolvencia que afecta al deudor y se extiende a sus acreedores y a terceros (por ejemplo, a 
los acreedores de sus acreedores, trabajadores y otros interesados "stakeholders"). En estos casos, el deudor no puede atender sus obligaciones a medida que vencen y, por ello, surge un conflicto de intereses entre todas las personas que han tenido alguna relación jurídicopatrimonial con el insolvente.

El Derecho concursal es la respuesta del ordenamiento jurídico a la problemática que acabamos de describir. En efecto, el Derecho concursal es una rama del ordenamiento jurídico, principalmente privada pero con ciertos matices de Derecho público, a la cual podemos atribuir una naturaleza esencialmente funcional, en el sentido de que encuentra su justificación en la solución de los conflictos que produce la insolvencia del deudor.

El Derecho de la insolvencia ha cumplido varias funciones a lo largo de su historia; en un primer momento, cumplió una función exclusivamente solutoria, identificada con la satisfacción de los acreedores perjudicados por la insolvencia del deudor cuyo patrimonio resultaba insuficiente para el cumplimiento de sus obligaciones. En una segunda etapa (que podemos extender hasta el momento actual), el Derecho concursal ha desarrollado una función conservativa de la empresa en crisis, principalmente a través de instrumentos reorganizativos de los elementos que integran la empresa. Asimismo, el Derecho de la insolvencia ha desempeñado una función represiva de los deudores que no pueden satisfacer de forma ordenada los créditos que asumen.

Pues bien, en el contexto de las crisis económicas sufridas por la mayoría de los países industrializados desde finales del siglo XX, puede advertirse un mayor protagonismo de la función conservativa del Derecho concursal. En efecto, en los últimos años ${ }^{1}$ ha emergido una "cultura concursal" basada en la promoción a ultranza de la función conservativa. Así pues, los legisladores de diferentes Estados, tanto europeos como latinoamericanos, han acometido sendas reformas de sus normativas de insolvencia con la finalidad de reforzar el convenio como solución conservativa a la crisis de la empresa o para implementar nuevos instrumentos jurídicos de carácter conservativo².

Este artículo tiene como objetivo exponer las dinámicas en la configuración de la función del Derecho concursal presentes en las recientes intervenciones legislativas llevadas a cabo por algunos países europeos y latinoamericanos. Asimismo, tomando en consideración las citadas reformas del Derecho concursal, analizaremos desde una perspectiva económica-funcional las tensiones existentes entre la función solutoria y conservativa ${ }^{3}$.

Aunque la configuración de la finalidad (y de la función) del Derecho concursal constituye un principio de política legislativa y, por tanto, corresponde al legislador decidir la finalidad del procedimiento concursal (o de los procedimientos concursales) que se integran en cada

\footnotetext{
1. Cfr. La normativa concursal promulgada por la mayoría de los países a raíz de la crisis sanitaria provocada por la Covid-19 merece una mención especial en esta genérica referencia temporal que hacemos en el texto. Con todo, debido a su naturaleza coyuntural y extraordinaria, dichas novedades no son objeto de este trabajo.

2. Cfr. (DASSO, 2012). Un claro ejemplo de esta voluntad de promover la conservación de la empresa en crisis lo encontramos en el auge de los institutos preconcursales, los cuales tienen como finalidad esencial prevenir la insolvencia (o bien detectar la crisis antes de que esta se agrave) evitando la apertura de un procedimiento concursal y conservando la empresa del deudor. Sin perjuicio de las particularidades propias de cada ordenamiento jurídico, estos instrumentos preconcursales se caracterizan por su naturaleza preventiva de la crisis y eminentemente privatista.

3. Cfr. Dejamos a un lado, por tanto, el estudio de la función represiva del Derecho concursal. Principalmente por motivos de claridad expositiva y, en parte, por la menor relevancia que en la actualidad supone la función represiva de los procedimientos concursales. En cualquier caso, ello no excluye la necesidad de analizar críticamente determinadas instituciones concursales que todavía hoy permanecen en algunos estados, y en las que subyace un claro espíritu represivo de la insolvencia; a modo de ejemplo puede citarse la sección de calificación en el procedimiento concursal español.
} 
ordenamiento jurídico ${ }^{4}$, consideramos que es necesario un ejercicio de análisis que permita al interprete conocer con precisión cuál es la finalidad de las instituciones concursales y razonar acerca de su funcionalidad. Y ello en la medida en que dicha finalidad debe impregnar la interpretación de las normas concursales y guiar la actividad de los órganos involucrados en los procedimientos concursales.

Por supuesto, no es objetivo de este trabajo analizar exhaustivamente el Derecho concursal de los distintos países que se toman como referencia. Ni siquiera abordar de manera completa el estudio de la función (o funciones) de los distintos procedimientos concursales que se citan. En realidad, el propósito de estas líneas es más limitado: se circunscribe a ofrecer algunas ideas básicas sobre las funciones tradicionalmente atribuidas al Derecho concursal y sobre las nuevas tendencias presentes en las reformas de los procedimientos concursales de algunos países de Europa y de Latinoamérica.

El objetivo propuesto se desarrollará en cinco apartados claramente diferenciados: en el primero, trataremos de justificar la relevancia interpretativa de la función atribuida al Derecho concursal; en el segundo, haremos una breve referencia a las funciones tradicionalmente asignadas al Derecho concursal; en el tercero, se expondrán algunas reformas legislativas que avanzan decididamente en el fortalecimiento de la función conservativa de los procedimientos concursales; en el cuarto apartado, analizaremos la relación entre ambas funciones, solutoria y conservativa, desde una perspectiva económico-funcional; finalmente, y como resultado de este proceso, trataremos de conjugar los apartados anteriores para extraer algunas conclusiones que, a nuestro parecer, permitirán entender mejor el fenómeno apuntado.

\section{La relevancia interpretativa de la función del Derecho concursal}

Cualquier creación legislativa responde a un fin y, más ampliamente, la determinación de este fin es el resultado de una ponderación previa por parte del legislador de los intereses en conflicto (Tirado, 2009). Al decidirse a favor de uno u otro de los intereses en conflicto, el legislador buscará la realización práctica de una finalidad. Por ello, puede decirse que desentrañar estos extremos es el primer paso para el análisis e interpretación de una institución jurídica.

En lo que respecta de forma específica al Derecho concursal, la insolvencia del deudor crea un conflicto de intereses (principalmente entre el deudor y sus acreedores). Y este conflicto obliga al legislador a crear una ley que establezca los criterios para resolverlo.

En efecto, el Derecho concursal es un instrumento reactivo del sistema económico legal (Tirado, 2009) que tiene como finalidad general solucionar los conflictos de intereses que surgen en el mercado provocados por la insolvencia del deudor. Su existencia constituye, por tanto, la plasmación de los valores del legislador en lo concerniente a los intereses que entran en conflicto en una situación de insolvencia.

4. Cfr. (Tirado, 2009). A la hora de determinar la finalidad del procedimiento concursal, el legislador puede optar entre hacerlo de forma directa (dedicando una norma específica a determinar la finalidad del procedimiento) o bien de forma indirecta a través del propio contenido de las normas que conforman el procedimiento en cuestión. 
Pues bien, dicha naturaleza instrumental confiere especial relevancia interpretativa a la finalidad perseguida por el Derecho concursal; puede decirse que el instrumento metodológico más apropiado para acercarse al estudio de esta rama del ordenamiento jurídico es aquél basado en los argumentos teleológicos (Tirado, 2009). Por ello, a diferencia de otros ámbitos jurídicos (como el Derecho societario donde puede asumirse que el legislador persigue objetivos de carácter general como el bienestar de la sociedad en su conjunto), la finalidad que se atribuya al Derecho concursal debe ser necesariamente más concreta.

Un Derecho concursal eficiente capaz de dar respuesta a la situación de insolvencia (y al conflicto de intereses que puede surgir entre las partes implicadas) debe perseguir una finalidad concreta. No basta con afirmar que se busca la solución a la crisis económica; este es un objetivo demasiado genérico. El intérprete y los operadores que participan en el procedimiento deben tener claro en todo momento cuál es la finalidad del Derecho concursal o, en particular, del procedimiento concursal en cuestión.

Así pues, el intérprete debe identificar cuál es la función (o funciones) del Derecho concursal. Naturalmente, este ejercicio estará determinado por el contenido de las normas, de forma que en los casos en que el legislador haya fijado de forma expresa la finalidad del Derecho concursal o de una institución jurídica, la labor del interprete será menor; en otro caso, si el legislador no tipifica de forma expresa cuál sea la finalidad, corresponderá al interprete extraerlo del conjunto del sistema.

En suma, la función del Derecho concursal (o, en su caso, de los procedimientos que lo integran) debe impregnar la interpretación de los preceptos concursales y guiar la actividad de los órganos del procedimiento concursal. Esta labor permitirá delimitar cuáles son los márgenes interpretativos y proporcionar seguridad jurídica a las partes afectadas por la insolvencia.

\section{Las funciones tradicionales del Derecho concursal}

Si atendemos a la historia comparada de los procedimientos concursales desde el Derecho romano hasta nuestros días, podemos identificar unas líneas evolutivas relativamente homogéneas. Históricamente, el primer instituto concursal fue la quiebra, que surge a partir del siglo XIII en el seno de los estatutos de las corporaciones mercantiles de las ciudades medievales italianas (Pulgar, 1994). La quiebra se configuró como un instituto esencialmente punitivo con la finalidad principal de satisfacer a los acreedores a través de la liquidación del patrimonio del deudor.

Asimismo, de forma simultánea a la evolución normativa de la quiebra como instituto concursal, los estatutos medievales dedicados a regular la actividad del comerciante comenzaron a incorporar un sistema de convenios entre el deudor y sus acreedores como solución alternativa a la liquidación (Pulgar, 1994). Estos convenios se presentaron como una solución a la insolvencia de carácter negociada y conservativa, pero con una finalidad exclusivamente solutoria. 
En una etapa posterior, desde finales del siglo XIX, se comenzará a incorporar en la mayor parte de los ordenamientos jurídicos una modalidad de convenio preventivo judicial (Pulgar, 1994). Este convenio se configuró como un instrumento concursal de carácter judicial situado en un momento anterior a la declaración de quiebra. En cualquier caso, debe tenerse en cuenta que la conservación de la actividad económica que viniera desarrollando el deudor no constituía la finalidad de esta clase de convenios, sino únicamente un medio para la consecución de su auténtica finalidad: la satisfacción de los acreedores. Tal y como indica Pulgar, (1994) “En este periodo histórico, no será la viabilidad económica de la empresa lo que delimitará la apertura del convenio frente a la quiebra, sino una especial cualificación del deudor comerciante" (p.29).

Con carácter general, las sucesivas reformas en el Derecho concursal que se producen en el siglo XX mantienen los tradicionales institutos concursales, la quiebra y los convenios (sin perjuicio de las variaciones terminológicas y procedimentales de cada país). No obstante, sí podemos advertir que se produce un cambio en la concepción de la función que cumplen estos institutos concursales. La quiebra y los convenios dejan de tener una finalidad exclusivamente solutoria (basada en la satisfacción de los acreedores), para incorporar una función principal (no instrumental) consistente en la conservación de la empresa en crisis por medio del convenio, sea este de carácter judicial o extrajudicial (Pulgar, 1994).

Asimismo, de forma paralela al fenómeno descrito en el párrafo anterior, a lo largo del siglo XX algunos países comienzan a configurar otros institutos concursales conservativos de carácter reorganizativo (distintos de los convenios tradicionales) aplicables exclusivamente a empresas con trascendencia social o de grandes dimensiones en cuya actividad está presente un interés público en su conservación; v.gr., el procedimiento de amministrazione straordinaria en el Derecho concursal italiano. Estos institutos se caracterizaron por incorporar, además, de los tradicionales modos de arreglo del pasivo (quitas y/o esperas), otras medidas de carácter esencialmente económico-financiero ${ }^{5}$.

En este sentido, debe destacarse que a partir de la segunda mitad del siglo XX se comienza a observar un mayor interés de algunos Estados por solucionar la crisis económica de la empresa (Santini, 1982); y ello en la medida en que las empresas ya no se limitan a arriesgar el capital de los socios, sino que implican múltiples intereses en su actividad (inversores, entes que intermedian en la concesión de crédito). En consecuencia, puede reconocerse un avance desde la concepción privatista y subjetiva del Derecho concursal clásico hacia una concepción publicista, socializadora y objetiva.

A partir de este último período, la mayoría de los ordenamientos jurídicos que cuentan con un Derecho concursal avanzado abogan por incorporar la función conservativa, en mayor o menor medida, a sus procedimientos concursales. Tal y como advertía el maestro Olivencia: "Ninguna reforma concursal puede hoy ignorar ese planteamiento, ni puede calificarse de satisfactoria ninguna ley que no acierte a compatibilizar el interés de los acreedores con la protección del principio de conservación de la empresa" (Olivencia, 1982, p. 109).

5. Cfr. Las características de los institutos reorganizativos, inicialmente reservadas a las empresas de particular relevancia, se irían extendiendo hasta incluirse en los convenios aplicables a cualquier deudor. 
En cualquier caso, conviene precisar que la mayoría de la doctrina de finales del siglo XX consideraba que la función conservativa del Derecho concursal no podía ser opuesta a la solutoria (Olivencia, 1982). Así pues, el trascurso ideal del procedimiento concursal sería aquel en el que mediante la intervención de los órganos judiciales en el seno del procedimiento pueden compatibilizarse ambas funciones, la conservación de la empresa del deudor y la satisfacción de sus acreedores.

\section{El protagonismo de la función conservativa en las últimas reformas concursales de algunos ordenamientos jurídicos}

Durante las últimas décadas, las reformas operadas en el Derecho concursal han tenido un objetivo claro: la conservación de la empresa en crisis. Esta tendencia se ha puesto claramente de manifiesto en las recientes reformas del Derecho concursal llevadas a cabo por distintos países, tanto de Europa como de Latinoamérica.

En lo que respecta al Derecho continental europeo, abordaremos la legislación concursal de España, Alemania e Italia. Si comenzamos poniendo el foco de atención en Alemania, hasta la promulgación de la Insolvenzordnung el 5 de octubre de 1994 (en adelante InsO), el Derecho concursal alemán estaba integrado por el concurso (procedimiento liquidatorio) regulado en la Konkursordnung de 1887, y por la ley de convenio preventivo (Vergleichsordnung) de 1935. La InsO unificó ambos procedimientos (conservativo y liquidatorio) e introdujo un renovado procedimiento concursal, el cual puede conducir a la reorganización o a la liquidación del patrimonio del deudor (Schmidt, 2002).

Desde su entrada en vigor, la Ins 0 también ha sufrido importantes reformas ${ }^{6}$; entre ellas, destaca la operada por la ley para la mejora de reestructuración de empresas (Gesetz zu weiteren Erleichterung der Sanierung von Unternehmen, ESUG), que entró en vigor el 1 de marzo de 2012 y que modificó sustancialmente algunas normas de la InsO. Los principales objetivos de esta reforma fueron: facilitar la reestructuración de empresas que se encuentren en dificultades financieras; simplificar el proceso de adopción del plan de insolvencia; y priorizar el régimen de intervención de las facultades patrimoniales del deudor frente al régimen de suspensión (Ferré, Keller, 2012).

En España, la Exposición de Motivos de la Ley 22/2003, de 9 de julio, Concursal, declaraba expresamente que el convenio es la "solución normal" del único procedimiento concursal (el concurso de acreedores). De forma similar a la normativa alemana, la Ley concursal de 2003 sufrió numerosas reformas (en 2009, 2011, 2014 y 2015), en las que el legislador español trató de favorecer la función conservativa del concurso a través de diferentes vías, las cuales pueden simplificarse en las siguientes: la introducción de institutos preconcursales similares a los previstos en el Derecho comparado; mejora de las posibilidades de enajenar de forma unitaria la empresa del deudor en la primera fase del procedimiento concursal; y el reforzamiento del convenio como solución al concurso.

6. Cfr. Hopt, K. J., Steffek, F., (2010).Un análisis en profundidad del contenido y de la naturaleza de estas reformas. 
Una mención especial merecen las medidas adoptadas por el legislador español para estimular la celebración de convenios entre el deudor y sus acreedores con la finalidad de impulsar la conservación de la actividad empresarial. En esta línea, puede citarse la Ley 9/2015, de 25 de mayo, de medidas urgentes en materia concursal ${ }^{7}$, la cual trató de fomentar la conservación de la actividad empresarial a través del establecimiento de una disciplina específica para vender unidades productivas del deudor durante la fase común (artículo. 43.4 LC), y mediante la reducción de las mayorías previstas en la normativa societaria para que la junta general de socios apruebe la capitalización de créditos que constituya el contenido del convenio (artículo. 100.2.II párrafo. LC). La norma citada también pretendía impulsar la celebración de convenios de continuación de la actividad empresarial mediante la introducción de otras reformas, por ejemplo, la supresión de la necesidad de autorización judicial a las propuestas de convenio que excedieran los límites de quita o espera (artículo. 100 LC), o el establecimiento de mayorías de arrastre en el voto de los acreedores privilegiados que, de producirse, provocan la extensión del convenio al resto de créditos de la misma calificación (artículo. 134.3 LC).

Por su parte, el reciente Real Decreto Legislativo 1/2020, de 5 de mayo, por el que se aprueba el texto refundido de la Ley Concursal (en adelante TRLC), el cual ha entrado en vigor el 1 de septiembre de 2020 (DF 2. ${ }^{a}$ ), acoge la tendencia conservativa del Derecho concursal que venimos señalando. En efecto, el apart. II (penúltimo párrafo) de la Exposición de Motivos del TRLC dispone expresamente:

El Derecho concursal se reivindica como una herramienta fundamental para la conservación de tejido empresarial y empleo; y de ello es consciente el legislador y la propia Unión Europea que ha desarrollado una importante iniciativa normativa a través de Directivas como la mencionada inmediatamente antes.

En cualquier caso, la propia naturaleza de la norma ha vetado la posibilidad de introducir novedades de fondo que avancen en la función conservativa del procedimiento concursal ${ }^{8}$.

En Italia, sin perjuicio de las numerosas reformas sufridas por el Legge Fallimentare (Regio Decreto 16 marzo 1942, n. 267), destacamos el Decreto legge n. 35 de 14 de marzo de 2005, convertido en Ley n. 80 del 14 de mayo de 2005, el cual instauró una nueva regulación del concordato preventivo, de los acuerdos de refinanciación "blindados" e incorporó en el ordenamiento italiano la figura del acuerdo de reestructuración de deudas. Esta reforma tuvo como propósito fomentar la función conservativa del Derecho concursal italiano y, en particular, del concordato preventivo, como procedimiento que permite al deudor (en caso de éxito) evitar la liquidación (Pacchi, 2013).

Asimismo, en el Derecho concursal italiano destaca la reciente aprobación del Codice della crisi d'impresa e dell'insolvenza, mediante Decreto Legislativo 12 gennaio 2019, n. 14 (en

7. Cfr. la Ley 9/2015 en el segundo apartado de la Exposición de Motivos, establece expresamente que la finalidad de la reforma es "facilitar en la mayor medida posible la continuación de la actividad empresarial, lo cual ha de redundar no sólo en beneficio de la propia empresa, sino también de sus empleados y acreedores y de la economía en general".

8. Debe tenerse en cuenta que la Disposición final octava de la Ley 9/2015, de 25 de mayo, de medidas urgentes en materia concursal, habilitó al Poder Ejecutivo de España para aprobar un texto refundido de la Ley 22/2003, de 9 de julio, Concursal, con el objetivo de consolidar en un texto único las modificaciones incorporadas desde su entrada en vigor; dicha autorización incluía la facultad de regularizar, aclarar y armonizar los textos legales que debían ser refundidos. El Real Decreto Legislativo $1 / 2020$, de 5 de

mayo, constituye, por tanto, el cumplimiento del encargo realizado por las Cortes Generales al poder ejecutivo de España. 
adelante CCII) ${ }^{9}$. El CCII deroga la Legge fallimentare introduciendo cambios notables en la normativa concursal italiana, aunque mantiene el esquema tradicional de los procedimientos concursales para la generalidad de los deudores: el concordato preventivo y el fallimento, denominado ahora liquidazione giudiziale (Lo Cascio, 2019).

En relación al contenido del CCII debe llamarse la atención sobre el artículo 84 "Finalitá del concordato preventivo", el cual dispone en su primer apartado que "Con il concordato preventivo il debitore realizza il soddisfacimento dei creditori mediante la continuita' aziendale o la liquidazione del patrimonio". Como puede comprobarse, el precepto apuesta claramente por la finalidad conservativa del procedimiento, aunque configura el concordato como un medio para satisfacer a los acreedores.

Si atendemos a los países de Latinoamérica, en Argentina, la disciplina concursal está regulada por la Ley N. ${ }^{\circ} 24.522$ de Concursos y Quiebras, la cual configura, a grandes rasgos, dos procedimientos: el concurso preventivo, el cual está dirigido a la obtención de un acuerdo entre el deudor y los acreedores; y la quiebra, que es un procedimiento tendente a liquidar el patrimonio del deudor para pagar a los acreedores con el producto de la venta (Redondo, 2011).

En este sentido, puede citarse la Ley 26.684 del 2011 de reforma de la Ley N. ${ }^{\circ} 24.522$, cuyo propósito es impulsar la función conservativa de empresas en crisis (Negre de Alonso, 2012). En efecto, la reforma está orientada a dar mayor protección al crédito laboral y mayor protagonismo a los trabajadores y acreedores laborales en la recuperación de la empresa, facilitándoles la continuación de la explotación y su posterior adquisición bajo la forma de una cooperativa de trabajo. Como era de esperar, la doctrina no tardó demasiado en advertir de las deficiencias de esta nueva regulación y de los innumerables problemas de orden práctico que podría plantear la puesta práctica de este "método" de conservar empresas (Boretto, 2013).

En relación con la legislación concursal de Colombia, la Ley n. 1116 de 2006 es la encargada de regular la situación de insolvencia de las empresas (dicha norma no es aplicable a personas físicas no comerciantes) ${ }^{10}$. A este respecto, puede citarse el primer artículo de la Ley $n .^{0} 1116$, el cual establece que el régimen judicial de insolvencia que se regula en la citada ley: "Tiene por objeto la protección del crédito y la recuperación y conservación de la empresa como unidad de explotación económica y fuente generadora de empleo...". Como ejemplo de la predilección del legislador colombiano por la conservación de la empresa podemos apuntar que el concurso se inicia a través de un proceso de reorganización, cuyo objetivo es alcanzar un acuerdo de reorganización entre el deudor y los acreedores dentro del plazo estipulado en el auto de apertura (Sotomonte, 2008).

Asimismo, el proceso de liquidación judicial ocupa una posición secundaria en el Derecho concursal colombiano (Mejan, 2014); y se contempla la posibilidad de celebrar un acuerdo de

9. Cfr. Con respecto a la entrada en vigor del CCII, debe tenerse en cuenta lo dispuesto por el Decreto legge 8 aprile 2020, n. 23 (relativo a "Misure urgenti in materia di accesso al credito e di adempimenti fiscali per le imprese, di poteri speciali nei settori strategici, nonché interventi in materia di salute e lavoro, di proroga di termini amministrativi e processuali", el cual establece un diferimiento de la entrada en vigor del CCII al 1 de septiembre de 2021 (salvo las excepciones previstas en el art. 389.2 CCII). 10. Cfr. Fuentes-Mancipe, M.M (2020). Editorial. Inciso, 22(1). Las consideraciones que se realizan en el texto no tienen en cuenta, por su carácter excepcional y transitorio, la normativa en materia concursal emitida como consecuencia de la crisis sanitaria provocada por la Covid-19. Deben tenerse en cuenta en este sentido el Decreto 560 del 15 de abril de 2020, el Decreto 772 del 03 de junio de 2020 y el Decreto 842 del 13 de junio de 2020; estas disposiciones normativas fueron expedidas por el presidente de la república de Colombia y tienen como finalidad contribuir a la recuperación y conservación de las empresas en crisis, especialmente de las pequeñas y medianas empresas. 
reorganización empresarial durante la tramitación de la liquidación para de esta forma evitar la destrucción de la empresa (artículo 66).

Por tanto, la evolución del Derecho concursal colombiano también evidencia la tendencia hacia la promoción de la función conservativa; y ello sin perjuicio de la búsqueda de un equilibrio entre ambas finalidades, solutoria y concursal (Rodríguez Espitia, 2007; Sotomonte, 2008).

En suma, estos concisos acercamientos a las legislaciones concursales de algunos países permiten advertir (simplificando y con todos los riesgos que implican los reduccionismos) un notable viraje hacia la función conservativa del Derecho concursal, la cual queda plasmada en las recientes reformas llevadas a cabo en este ámbito.

\section{Las tensiones entre la función conservativa y la solutoria}

Sin perjuicio de lo expuesto en el apartado anterior, debe reconocerse que con carácter general, ambas funciones: solutoria y conservativa, están presentes en la mayoría de las normativas concursales de los países mencionados.

Ahora bien, desde un punto de vista subjetivo, satisfacer a unos sujetos puede implicar perjudicar a otros; por ejemplo, la reorganización o la venta unitaria de la empresa puede beneficiar a los trabajadores y al titular de la empresa a costa de los acreedores si esta solución a la insolvencia no se adopta siguiendo criterios de eficiencia y de racionalidad económica. Por ello, es necesario analizar la forma en la que, desde una perspectiva económico-funcional, se relacionan (o deberían relacionarse) ambas funciones del Derecho concursal.

(i) En lo que respecta a la función solutoria, la necesidad de articular un sistema concursal que proteja y, en la medida de lo posible, garantice la satisfacción de los créditos concursales de forma prioritaria frente a la conservación de la empresa se fundamenta en varios argumentos.

Desde una perspectiva jurídica, los acreedores son los principales interesados del procedimiento concursal. En efecto, si tomamos en consideración las normas generales de tutela del crédito, los acreedores ostentan una serie de derechos contra el deudor: un derecho de restitución en las condiciones pactadas y un derecho de agresión sobre el patrimonio del deudor si este incumple sus obligaciones.

En segundo lugar, desde una perspectiva financiera-contable, el interés del concurso puede identificarse con el interés de los acreedores si el deudor está en una situación de desbalance o insuficiencia patrimonial. En estos casos, los propietarios de la empresa han perdido la totalidad de su inversión, ya que los únicos recursos que se encuentran financiando las inversiones (activos) son los recursos ajenos (pasivos). Desde esta perspectiva, puede decirse que los acreedores son los titulares económicos de los activos del deudor.

(ii) Una de las posibles consecuencias de dar prioridad absoluta a las pretensiones de los acreedores es que la actuación de estos puede terminar por destruir la empresa (entendida como ente que conjuga distintos elementos personales y materiales para el ejercicio de una 
actividad económica). Por ello, mediante la función conservativa, el Derecho concursal se erige como un instrumento jurídico para reestructurar la empresa en crisis.

Ahora bien, lo anterior no puede suponer un obstáculo para considerar que la función conservativa debe estar sometida a unos límites, los cuales derivan, en gran medida, del análisis económico-funcional.

En primer lugar, conviene precisar que aunque existe una creencia generalizada de que el valor de la empresa en funcionamiento es mayor que su valor de liquidación, ello dependerá de la viabilidad de la empresa. Desde una perspectiva concursalista, el valor de una empresa en funcionamiento depende de la capacidad para generar recursos financieros, de su capacidad de pagarlos y del coste medio del capital al que la empresa tendría que descontar los flujos netos de caja esperados al momento de realizar la valoración (Gurrea, 2015). Por otro lado, el valor de liquidación dependerá del valor de los activos una vez deducidos lo pasivos, tomando como referencia los valores de mercado.

Por consiguiente, si el valor de la empresa en funcionamiento es negativo (inferior al valor de liquidación) se puede considerar que la empresa es inviable (se encontraría en una situación de economic distrees). En cambio, si el problema consiste en una mera imposibilidad de pagar (financial distress), podría considerarse que la empresa es viable, pues su valor en funcionamiento sería positivo. De este modo, para que la reorganización de una empresa en crisis sea eficiente desde una perspectiva económica debe tratarse de una empresa viable (en financial distress), y esta cualidad de la empresa vendrá determinada por su mayor valor en funcionamiento frente a su valor de liquidación.

Siguiendo este criterio, si la maximización del valor de la empresa se consigue a través de la venta de los activos y pasivos a terceros, la solución económicamente adecuada será la liquidación. En cambio, si el valor de la empresa en funcionamiento (esto es, a través del ejercicio de su actividad) es mayor que el valor previsible de liquidación de sus elementos, la solución más eficiente a la situación de crisis será la conservación de la empresa a través de su reestructuración (o su venta unitaria).

La alteración de esta regla, por ejemplo, para conservar determinadas empresas a pesar de su situación de inviabilidad económica, no será una solución eficiente a la crisis económica del deudor (Gurrea, 2015). Y ello debido a que los créditos quedarían insatisfechos en el importe que resulte de la diferencia entre el valor que se podría haber obtenido de la liquidación y el valor que efectivamente se obtiene con la reestructuración de la empresa.

Debe tenerse en cuenta, en este sentido, que la desviación del criterio de la conservación de empresas únicamente viables tiene efectos perjudiciales para la economía en su conjunto. En primer lugar por la ineficiente asignación de recursos que reduce el grado de satisfacción de los acreedores, lo que podría provocar a su vez una situación de insolvencia para los acreedores más expuestos al deudor. Además, tendría un coste de oportunidad para el sistema, en la medida en que imposibilitaría la utilización de activos materiales, intangibles y humanos de la compañía en otros usos alternativos que pudieran generar mayor riqueza, trabajo y bienestar social. 
En relación con lo anterior, desde una perspectiva ex ante, la imposición de soluciones conservativas ineficientes podría generar un aumento del coste de la deuda, ya que los acreedores se verán obligados a exigir mayores garantías o incluso serán reticentes a la concesión de créditos (Gurrea, 2015).

(iii) El convenio entre el deudor y sus acreedores como solución a la insolvencia es atractivo cuando la empresa es viable y los actuales socios administradores pueden aportar un valor añadido que no podría aportar un tercero adquiriente.

Por su parte, la liquidación unitaria será eficiente cuando la empresa sea viable pero existan terceros con mayores recursos, conocimientos o credibilidad para la gestión. Finalmente, la liquidación individual de los activos normalmente tendrá lugar cuando la compañía (o sus unidades productivas) no genere ningún valor añadido y, por tanto, una liquidación separada no destruya valor.

(iv) Con todo, no siempre la situación de crisis económica de la empresa se aborda desde una tensión entre la solución conservativa y la liquidativa. En algunas ocasiones solo cabe liquidación y, en otras, la solución conservativa es la idónea porque el deudor se encuentra en una situación de iliquidez.

En efecto, cuando la situación de insolvencia del deudor consiste únicamente en la imposibilidad de satisfacer regularmente sus obligaciones exigibles pero dispone de bienes y derechos por un importe superior a sus deudas, la solución más eficiente habría de pasar necesariamente por tutelar los intereses de los acreedores y los del deudor en la conservación de la empresa. En primer lugar, porque los acreedores no pueden considerarse los titulares económicos del patrimonio insolvente; aunque es cierto que su poder de agresión podría perturbar la empresa o, incluso, destruirla.

En estos casos, la solución más eficiente para satisfacer los créditos concursales sería la de un convenio con los acreedores basado en la continuidad de la actividad empresarial a través de su reestructuración. Por un lado, el deudor titular de la empresa se beneficiaría de esta opción porque evitaría las eventuales ejecuciones de los acreedores sobre los activos esenciales de la empresa; además, resultaría beneficiado del convenio o acuerdo con sus acreedores, pues las quitas y esperas incluidas en el pacto le permitirían mejorar su situación financiera (y, en última instancia, el valor de la empresa). Por su parte, los acreedores se beneficiarían del procedimiento concursal y de este tipo de solución porque se les permitiría canalizar sus pretensiones a través de un cauce ordenado que les ofrece ciertas garantías.

Con todo, se ha llegado a considerar que la preferencia por la conservación de la empresa en estos casos no implica que el Derecho concursal cumpla una función conservativa; se seguiría esta opción únicamente porque se trata de la solución más eficiente para el sistema (Gurrea, 2018). Desde esta perspectiva, la función del Derecho concursal ante la crisis de la empresa debería ser en todo caso la asignación eficiente de los activos, sea mediante una reorganización (si la empresa es viable y los acreedores confían en la gestión y honestidad de los socios/administradores), la liquidación y venta en bloque de la empresa o de sus unidades 
productivas (si la empresa o las unidades son viables y el problema de la compañía está en la gestión), o la liquidación individual de los activos (si no se genera ningún valor adicional manteniendo los activos de manera conjunta).

\section{Conclusiones}

Los procedimientos concursales están experimentando cambios de considerable magnitud hacia su configuración como instrumentos jurídicos mediante los que procurar la reestructuración de empresas que temporalmente atraviesen problemas financieros o de solvencia. Ello explica que las recientes reformas concursales hagan énfasis en la conservación de la empresa como institución de relevancia social, de generación de riqueza y de creación de puestos de trabajo.

No obstante, y a pesar de los incentivos políticos (instigados, en ocasiones, por las proclamaciones de distintos agentes sociales) para reformar el Derecho concursal promoviendo a ultranza la conservación de la empresa en crisis, consideramos que deben tenerse en cuenta los perjuicios que esta tendencia podría provocar en el largo plazo si se relega la función solutoria a un segundo plano.

Así pues, el Derecho concursal debe tener como finalidad esencial la maximización del grado de satisfacción de los acreedores. Y para lograr esta finalidad se deben proveer instrumentos eficientes que permitan conservar únicamente aquellas empresas viables. De esta forma, las soluciones tradicionales a la insolvencia, convenio y liquidación, quedarían configuradas como dos caminos alternativos para alcanzar la finalidad esencial del procedimiento concursal.

Asimismo, el Derecho concursal debe procurar, a través de instrumentos jurídicos eficientes, que las empresas viables no resulten abocadas a una liquidación individual de los elementos que la integran (por ejemplo, por una dilación excesiva de los trámites concursales o por una actitud obstruccionista del propio deudor que impida la reorganización).

\section{Referencias bibliográficas}

Boretto, M. (2013). Bases para una legislación actualizada del Derecho Comercial en la República Argentina. Revista Crítica de Derecho Inmobiliario, pp. 3195-3278.

Dasso, A. A. (2012). La paradójica inmisión de la extraconcursalidad en el nuevo derecho concursal del Siglo XXI. En: https://www.lawyerseekeurope.com/boletines/ficheros/.

Ferré, J., Keller, N., (2012). La reforma de la legislación concursal en Alemania. Anuario de Derecho Concursal, n. ${ }^{\circ} 27$, pp. 327-334.

Fuentes-Mancipe, M, (2020). Editorial. Inciso, 22(1); pp. 1-2. En: https://revistas.ugca.edu.co/ index.php/inciso/article/view/1042/1574.

Gurrea Martínez, A. (2015). Las tendencias actuales en la configuración del interés del concurso. Estudios jurídicos en memoria del profesor Emilio Beltrán. Valencia: Tirant lo Blanch, pp. 1523-1545. 
Gurrea Martínez, A.(2018). El Derecho concursal en España: Problemas estructurales y propuesta de reforma. Madrid: Reus.

Lo Cascio, G. (2019). Il codice della crisi di impresa e dell'insolvenza: considerazioni a prima lettura. II fallimento e le altre procedure concorsuali, 3, pp. 263-277.

Mejan, L. M. (2014). Apuntes para un régimen de insolvencia para las microempresas. Libro homenaje al profesor Emilio Beltrán. Bogotá: Instituto Iberoamericano de Derecho concursal, pp. 575-592.

Negre de Alonso, L. T. (2012). Algunos aspectos sobre la reforma a la ley concursal $N^{\circ} 26.684$. Revista Argentina de Derecho Laboral y de la Seguridad Social, N. ${ }^{\circ}$ 3. En https:// ar.ijeditores.com/articulos. php?idarticulo=48917\&print $=1$.

Olivencia, M. (1982). Los sistemas económicos y las soluciones jurídicas al estado de crisis empresarial. La reforma del Derecho de quiebra. Madrid: Civitas, pp. 99-121.

Pacchi, S. (2013). La quinta etapa de la reforma concursal italiana. Revista de Derecho Concursal y Paraconcursal, n. ${ }^{\circ}$ 18, pp. 375-393.

Pulgar Ezquerra, J. (1994). La reforma del Derecho Concursal comparado y español (Los nuevos institutos concursales y reorganizativos). Madrid: Civitas.

Redondo, F. (2011). El "salvataje" de la empresa insolvente en la legislación concursal argentina. Revisa de Derecho Procesal, n. ${ }^{\circ}$ 3-4, pp. 313-353.

Santini, G. (1982). Soluciones jurídicas al estado de crisis de la empresa en los sistemas de economía de mercado. La reforma del Derecho de quiebra. Madrid: Civitas, pp. 35-67.

Schmidt, K. (2002). Fundamentos del nuevo derecho concursal alemán. Estudios sobre el Anteproyecto de Ley Concursal de 2001, Madrid, pp. 15-41.

Sotomonte Sotomonte, S. (2008). Aspectos sustantivos del régimen de insolvencia. Revista e-Mercatoria. En: https://www.emercatoria.edu.co/PAGINAS/actualidad/aspectos.pdf

Tirado, I. (2009). Reflexiones sobre el concepto de "interés concursal" (Ideas para la construcción de una teoría sobre la finalidad del concurso de acreedores). Anuario de Derecho Civil 3, pp. 1055 - 1108. 